This is a self-archived version of an original article. This version may differ from the original in pagination and typographic details.

Author(s): Ikävalko, Heini; Hökkä, Päivi; Paloniemi, Susanna; Vähäsantanen, Katja

Title: Emotional competence at work

Year: 2020

Version: Accepted version (Final draft)

Copyright: @ Emerald Publishing Limited

Rights: CC BY-NC 4.0

Rights url: https://creativecommons.org/licenses/by-nc/4.0/

Please cite the original version:

Ikävalko, H., Hökkä, P., Paloniemi, S., \& Vähäsantanen, K. (2020). Emotional competence at work. Journal of Organizational Change Management, 33(7), 1485-1498.

https://doi.org/10.1108/jocm-01-2020-0024 
Accepted for publication in Journal of Organizational Change Management (ISSN:0953-4814, published 27 August 2020),

DOI 10.1108/JOCM-01-2020-0024

\section{Emotional competence at work}

○ (Purpose) The study investigated emotional competence at work, and elaborated emotional competence in relation to socio-cultural aspects of emotions at work.

○ (Design/Methodology/Approach) Emotional competence at work was explored via interviews, surveys, and observations. The study was conducted over one year, during which an emotion-training intervention was conducted within a medium-sized company, operating in the healthcare sector.

○ (Findings) The study shed light on emotional competence at work, identifying three domains: Individual emotional competence, Emotional competence within interactions, and Emotional competence embedded in workplace practices.

○ (Research limitations/Implications) This study was conducted in one organization.

○ (Practical implications) Organizational developers are recommended to implement activities such as training interventions in order to build emotional competence; this applies not only at the individual level, but also to achieve interaction among members of the organization, within collective workplace practices.

- (Originality /value) Previous studies on emotional competence have been limited to the individual level. The sociocultural approach to emotional competence adopted in this study recognizes - in addition to the individual and interactional level of emotional competence - emotional competence at work as related to practices at work.

Keywords: Emotion, competence, work, intervention

\section{Introduction}

Emotions play an important role at many levels in organizational life and change. Empirical evidence has shown that emotions affect how individuals experience change (Dasborough, Lamb \& Suseno, 2015), or adopt new beliefs (Vuori \& Virtaharju, 2012). Emotions are also important for social processes among organizational members, influencing how they implement strategies in 
organizations (Huy, 2011). The multiple interpretations and emotional complexities that operate among organizational actors are highly relevant for understanding processes of change in organizational lives (Manzoor et al., 2018). The relevance is all the greater as organizational changes intensify and become more complex. Research on both planned and ongoing changes, and on how these interact, has led to more holistic approaches to organizational change, and to a better awareness of the unseen tensions and layers within organizational change (Livne-Tarandach \& Bartunek, 2009). It is envisaged that by attending to the emotional dimensions, actors may become more sensitive to the processes at work in ongoing transformational change (Tsoukas \& Chia, 2002), and be able to positively implement awareness-based change (Senge, Scharmer \& Jaworski, 2005).

In efforts to realize and support change, there is a need to develop techniques for nurturing awareness and empathy within organizational interactions (Rill, 2016), and to promote capacity building (Senge 2006). Previous research has shown that emotionally competent individuals positively influence work performance (Kim et al., 2009). This highlights the need to assist individuals in developing emotional abilities in the workplace, with implications for organizational development and change. The focus on the emotional dynamics of the organization can build organizations' overall emotional capability, and facilitate organizational change and renewal (Huy, 1999; 2015).

Various kinds of workplace interventions have been shown to be effective (e.g. Schutte, Malouff \& Thorsteinsson, 2013) in promoting emotional competence. However, many interventions and studies on emotional competence have taken an individualistic perspective (cf. Ashkanasy, 2003). Much less is known about how emotional competence is embedded in workplace practices and interactions, and how it is resourced (supported/inhibited) by contextual factors such as organizational cultures and values, social rules, discourses, or physical circumstances. This kind of understanding is lacking, even if scholars have emphasized that in studying emotions, one needs to understand the role of the organizational context, the events within it (Fehr et al., 2017), and its routines (Ashkanasy et al., 2017). It is somewhat surprising that there has been so little discussion on workplace practice in the literature on emotional competence. Consequently, the present study examined how emotional competence was manifested at work in relation to an emotion-focused training intervention. 
One challenge in studying emotions at work lies in the variety of theoretical and conceptual approaches taken, operating at different levels of theoretical premises and analysis, and giving rise to a range of implications. Broadly speaking, two main theoretical approaches, namely psychological and sociological, have been utilized in addressing emotions within organizations. In psychological theories, emotions are primarily seen as matters of individual experience, and as essentially intrapsychic phenomenon (e.g. Ekman, 2016). The main premise of socially oriented views on emotion is that emotional expressions are dependent on learned rules, which are socially and culturally constituted. Hence, emotions are not seen as phenomena that exist only in the mind, but rather as entities that structure social interaction and its consequences (e.g. Hareli, Rafaeli \& Parkinson, 2008; Zembylas, 2007). For the purposes of this study, the authors adopted a sociocultural view on emotion that makes it possible to elaborate and explore emotional competence, including its links with organizational practices and interactions (e.g. Hökkä et al., 2019; Smith, 2017; Turner, 2007). The socio-cultural approach emphasizes that emotion is not just an individual and internal state, but is always experienced, perceived, and understood in particular social and cultural circumstances. This underlines the interpersonal nature of emotions as socially, culturally, and situationally perceived and communicated entities (Hareli et al., 2008; Ma, Miyamoto \& Tamir, 2018; Snyder, Heller, Lumian \& McRae, 2013). Furthermore, the approach encompasses a process focus on emotion, viewing emotions as dynamic and continuously varying experiences within everyday practices (Schutz \& DeCuir, 2002). This view underlines the importance of theorizing emotions as constantly changing meaningful experiences (Zembylas, 2007). The socio-cultural approach can shed light on everyday interactions and practices in the workplace, and also on the emotions and emotional competence of individuals. Following this perspective, the present paper addresses emotional competence as a construct that can be applied to an individual's work at different levels.

This paper focuses on emotional competence at work within a medium-sized company operating in the Finnish healthcare sector. In this organization, an emotion-focused training intervention, including six workshops, was conducted. The entire personnel of the company were invited to participate in the intervention, which aimed to support their emotional competence at work. The study aimed to identify the kinds of emotional competence at work manifested in the 
organization, and was conducted concurrently with the training intervention. Rather than merely reporting on the effectiveness of the intervention, this study sought to examine emotional competence within actual work settings, both during and after the intervention. The paper makes a theoretical contribution, in that it elaborates socio-cultural aspects of emotions at work, and provides insights into emotional competence by integrating individual, interactional, and practice-based aspects of emotions. From a practical perspective, the paper suggests a need to integrate individual, interactional, and practice-based insights into emotional competence, in efforts to enhance organizational change.

\section{Literature review}

Previous research on emotional competence has focused mainly on individuals, and on intrapersonal and interpersonal emotional information (Brasseur et al., 2013). Kim et al. (2009) refer to this aspect in terms of individuals' perceptions of their own emotional abilities on the following dimensions: understanding one's own and others' emotions, regulating and utilizing one's own emotions. The concept of emotional competence is often used as synonymous or strongly overlapping with emotional intelligence, i.e. as being "the capacity to reason about emotions, and of emotions to enhance thinking" (Mayer \& Salovey, 1997). In using the concept of emotional competence instead of emotional intelligence, scholars characterize it as something that can be taught and learned, though this issue has given rise to lively debates among EI scholars (Hodzic et al., 2018). Some authors have emphasized the social role of emotional competence, viewing it as an ability that people may display,

such that they recognize and manage their own emotions and those of others (Härtel, Gough \& Härtel, 2006).

A number of more sociologically-oriented scholars have attempted to capture the historical context and constitutive mechanisms that may play a role in emotional competence. This perspective pays particular attention to discourse and to rhetorical devices (Chiaburu \& Gray, 2008). The concept of emotional competence has also been introduced in recent literature on institutional theorizing; within this approach, personal experience and social performance are linked to the ethos of an institution, with emotional competence being linked in turn to the actor's role in the institutional order (Voronov \& Weber, 2016). 
This paper seeks to elaborate emotional competence at work. In using the concept of emotional competence, the paper highlights the notion that emotional skills and abilities can be learned, developed, and supported over time (cf. Wang, Wilhite \& Martino, 2016). The paper further deploys socio-cultural lenses in viewing emotional competence as embedded and enacted in everyday work practices. Emotional competence at work is defined as the ability to perceive, understand, recognize, express, and practice/apply emotions in the workplace. The present paper acknowledges both intraand interpersonal perspectives, meaning that emotional competence is related to one's own emotions and to those of others. Such a definition acknowledges the role of socio-cultural conditions (e.g. material circumstances, power, discourses) in the workplace, but sees individuals as subjects who can make choices concerning their own actions and behavior (Eteläpelto et al., 2013; Hökkä et al., 2017, 2019). It follows that emotional competence can be enhanced through training interventions. In accordance with this line of argument, emotional competence is not to be viewed as a personal capacity, trait, or disposition but rather as an ability that can be learned and developed over time.

Previous studies have indicated that training interventions provide means to enhance emotional competence at work. In line with this, writings on emotional intelligence have argued that emotional abilities can be taught and developed (Pool \& Qualter, 2012), that training can improve individuals' wellbeing and work performance (Schutte et al., 2013; Clarke, 2010a), and that education can improve individuals' emotional information processing and emotional literacy (Ashkanasy et al., 2009). Related writings have indicated that training in emotional skills may promote pro-social responses (Kemeny et al., 2012). A recent meta-study by Hodzic et al. (2018), covering 24 studies, concluded that EI training can indeed be effective. Training was especially effective in the cognitive domain, and in terms of understanding emotions. The meta-study also indicated that longer interventions manifested more beneficial effects.

Training in emotional competence may have beneficial effects in organizations; for example, beliefs in one's own capabilities may result in individuals using their emotional abilities to build a collective emotional climate (Kirk et al., 2008). Luthans et al. (2008) found that positive capital in the workplace can be developed via a training intervention. Furthermore, emotional skills may be beneficial for leaders, especially within team contexts (Ashkanasy et al., 2009). A study by Clarke 
(2010b) showed the powerful role of team-based learning with regard to emotional intelligence in the workplace. The positive effects emerged in relation to participation in team learning rather than to individual development. The study emphasized the importance of creating stronger relational bonds to support the development of emotional abilities.

Despite the studies conducted so far, there have been calls for more studies on the influence of specific human resource management (HRM) interventions and processes (Tse et al., 2018). The overall need is to better understand emotions in the workplace, and the ways in which training interventions might promote awareness of emotions within the everyday practice of organizations.

\section{Methods}

\section{The intervention: developing emotional competence in a healthcare company}

This study was conducted as part of a research project aiming to investigate the effects of emotion-focused intervention within a situation of organizational change. The data utilized in the present paper derived from one company participating in the project. The organization was a private, medium-sized company operating in the healthcare sector in Finland. As with other healthcare organizations, the company had to prepare for major changes due to state health reform. The reform had brought uncertainty to the healthcare market, involving, for example, many mergers and acquisitions over recent years. In seeking to address the wellbeing of their personnel, the managers of the company had negotiated a one-year development project with a consultancy organization specializing in emotions at work. The project was to be targeted at the entire personnel of the company.

The emotion-focused training intervention that took place was implemented in line with the socio-cultural perspective on emotions; it was envisaged that the program would support the development of individual skills, and that it would be integrated with the everyday practices of the organization. Two experienced trainers designed and implemented the intervention. During the process, they interacted with the company's steering group (consisting of three senior managers), the aim being to rescope the contents of the intervention if necessary. The overall goal of the intervention was to support participants' management of emotions at work, via the aspects of awareness, reflection, and understanding. 
The training intervention consisted of six thematic workshops, implemented over a one-year period (See Figure 1). The intervention started with a kick-off meeting, followed by six workshops, and a summarizing session three months later (within a development day). All the employees of the company were invited to participate. For each workshop, three identical, consecutive two-hour workshop sessions were organized. Each employee chose the workshop session that best fitted with his or her schedules. The number of participants per workshop varied from to 56 to 81 individuals. These were distributed fairly evenly, with a minimum of 13 persons and a maximum of 34 persons in a given session. The workshops were organized in a training facility outside the company's premises. With full participation, the intervention provided 15 hours of input.

Insert Figure 1. about here

Here, an example may be of assistance. The (third and fourth) workshops on positive and negative emotions were devoted to several emotions, such as joy, pride, sadness, anger, or frustration. The participants were instructed on the nature of these emotions and their causes and regulation. The trainers gave accounts of relevant studies carried out in the field. Their accounts were backed up with PowerPoint presentations; these gave further illustrations, summarized key points, and presented tools that participants could use. For example, one slide that listed 35 different emotions could be used in identifying different emotions in the workplace. Furthermore, a framework focusing on basic human needs supported the participants in such a way that they could identify the potential needs of their colleagues or customers within an interaction. Simple questions (e.g., "Does the other person feel understood or treated fairly by others?") supported the participants in analyzing interactions via this framework. Another tool, called "Raising the Level," identified different layers in a discussion. According to this tool, an interaction can at one extreme be characterized as an outpouring of emotions, and at the other extreme as a series of visionary descriptions. As a means of coping with the emotions in the interactions, the participants were supported in identifying the layers involved, and reacting to them accordingly. 
For homework between the workshops, the participants were given small assignments. For example, between the first and second workshop they were asked to observe and list the emotions they noticed during an ordinary workday at their workplace. The homework was shared and reflected on during the workshops. No deliverable assignments were required, but the participants were encouraged to make notes on the set assignments between the workshops.

\section{Data collection and participants}

A qualitative approach was used to answer the research question posed in the study. In applying an interpretivist account (cf. Sturdy 2003), the aim was to achieve a descriptive and processual understanding of emotional competence at work, in the context of the emotion intervention. Thus, rather than using quantitative methods (for example to obtain a measure of emotional intelligence), the focus was on gaining in-depth insights into the subjective experiences of individual organizational members. Longitudinal data were collected during the development project over a 13-month period (see Figure 1).

The study reported here utilized three kinds of data: 1) face-to-face semi-structured interviews, 2) written responses to open-ended questions from from Surveys 2 and 3 (see Figure 1), and 3) observational data from two leaders' meetings. The data collection and participants are summarized in Table 1. In line with the aim of the study, the data focused on the participants' experiences of the emotion-focused intervention, and on their descriptions regarding the usefulness and applicability of emotional competence in their everyday work. Thus, the three kinds of qualitative data had a shared focus, and were used to complement each other (Patton, 2002).

Insert Table 1 about here

The interviews, which took place in company premises, were conducted with 11 members of the organization representing different professions (both medical and non-medical). Their work included either direct end-customer interaction (with patients), or operations in the back office. The interview guidelines included themes focusing on daily work practices, and on the experiences of the 
emotion intervention (e.g. Have you had any take-aways for your daily work?). The survey data were drawn from two open-ended questions (posed immediately after the workshops and again five months later) concerning the participants' experiences of the workshops, and the potential usefulness of the workshops for their current work practice. The profiles of the respondents, including all professional positions, were similar in both surveys (seeTable 1), and represented the general profile of the personnel of the company. The observation data consisted of transcriptions of two leaders' meetings. Within these, the emotion intervention was discussed in more detail, as were also the field notes compiled by one of the authors.

\section{Data analysis}

The data were analyzed via thematic analysis, i.e. a process of determining the core meanings of data (Patton, 2002). The analysis was inductive to the extent that it emphasized the significance of the participants' own perceptions concerning their work. However, the process was partly abductive (Mayan, 2009), in the sense that certain theoretical notions of emotions and emotional competence were directed at the analysis; these helped to guide the interpretation process, but were not used as pre-existing coding frames or categories for the data.

The thematic analysis procedures introduced by Braun and Clarke (2006) were followed. Thus, the authors first familiarized themselves with the data by reading the entire material. Next, initial codes were generated for the transcripts of the interviews, and for the observations and open-ended responses in the surveys. This was initiated by coding those parts of the data that reflected the participants' experiences. For example, the following authentic quotation from one of the interviews was coded as "the interviewee describes how her knowledge on emotions has increased":

So some things have maybe been familiar to me, or you could say I've come to realize them without being able to name them, but yeah, there's maybe been acquisition of knowledge, so new knowledge, and a new perspective on things, (...) so it's been, well, a learning situation for me, so that there's been real knowledge linked to it...(Interview)

This phase resulted in 195 codings capturing the individuals' experiences. In the next phase, these were analyzed in order to identify themes. As a result, 16 codes, such as "recognizing other 
people's emotional states" or "increasing knowledge about emotions" were identified. Next, these codes were thematically grouped and combined to form overarching themes. For example, those codes that reflected individually-centered learning or acquiring new knowledge were grouped together. This phase included also careful elaboration of candidate themes, taking note of whether they formed coherent and meaningful patterns with clear and identifiable distinctions between themes. This process of identifying the different kinds of themes on emotional competence at work was iterative rather than linear; thus, it involved continually moving back and forward within the data. The last phase included defining and naming the final themes, and involved naming the domains by their essential and meaningful characteristics. For example, Individual emotional competence was identified as obtaining new knowledge, tools, and skills, and also confidence.

As a result of the analysis, it was possible to identify three main themes (i.e. domains) of emotional competence (see detailed Findings below). These consisted of Individual emotional competence, Emotional competence within interactions, and Emotional competence embedded in workplace practices.

\section{Findings}

\section{Individual emotional competence}

The findings indicated that the participants developed individual competence during the intervention, in that they increased their knowledge concerning emotions, or became better aware of their own emotions, or took stock of their own existing knowledge regarding emotions. They also acquired new skills in the form of the tools provided by the training intervention.

The participants considered that they had increased their knowledge on emotions as a result of the studies, stories, and other kinds of information that had been shared during the workshops. For example, the lists of emotions shared by the trainers enabled the participants to label emotions in general. Furthermore, they described how their understanding of their own emotions had developed, and how they were better able to recognize their own emotions at work. The increased awareness of their own emotions made it easier to deal with the emotions. 
For me, the biggest use [of the training intervention] has been the increase in my understanding. I now understand why I react in a certain way. (Survey)

To recognize emotions, that is a great skill. For example, it is easier to get over one's irritations. (Survey)

The workshops provided the participants with tools and new approaches, so that they could test them and use them to solve everyday situations at work. For some participants, the tools acted as mental models, through which one could reflect on one's own actions. For example, one participant described how he took a photograph of the list of tools (printed on a postcard that had been given to participants) and uploaded it as a screensaver on his computer. The new tools offered the participants ways to solve everyday situations, as illustrated in the following reflection:

More and more, I'm aware of the role of emotions in interaction and guiding myself in my everyday work. I like using new approaches and tools to solve situations. I've seen the value of emotions even before the training, but now I can see emotion-loaded situations a bit differently; to evaluate, to coach myself, to see the everyday from a different view. (Survey)

Several participants indicated that the training intervention did not really provide new knowledge as such. Rather, it made individuals feel competent in their current knowledge and skills; thus it had a strengthening impact on the individual's competence at work.

The topic as such was not new to me. I use these skills in my everyday life. [But during the intervention] I realized that I've been very much able to use these. (Survey)

On the other hand, reflections on the challenge of coping with emotional situations at work, and on the need to practice the new tools, indicated increased awareness of the subject: 
These situations come at you suddenly. When you think about training in general - the gap between knowing and doing - in this topic it is wider than it generally is. (...) when you come across a situation where you need to cope with the other person's emotional state, or your own - to think how to open the toolbox in that situation, this needs a lot of practice. (Observation, team leaders' meeting)

\section{Emotional competence within interactions}

The participants described emotional competence at work in relation to interactions between organizational members in the workplace, or to customer interaction. A recurrent theme in the interviews was a sense of improved interaction with colleagues or customers. People described how they were better able to focus on the emotional state of the other person while interacting with $\mathrm{him} / \mathrm{her}$. This focusing made it possible to uncover and understand the actual need of the other person in that situation. When one focused on the emotion of the other person, it was easier to see the real need behind the emotion:

[Q: What have you learnt?] Focusing on the emotional state, for example, how to react when the other person panics when he makes his point. (Interview)

One respondent indicated that he had been dissatisfied with his supervisor's behavior. By applying one of the conceptual tools provided by the intervention, he was able to grasp the supervisor's perspective on the situation. He reflected on how this tool had made him understand that the supervisor was not being intentionally "difficult"; rather it was a matter of her own needs not being satisfied. Realizing this gave the respondent a feeling of improved wellbeing at work.

In identifying emotions, it also became easier to manage one's own emotions. If a colleague seemed to be at bad mood, rather than being drawn into a state of emotional contagion, the respondent felt that she was able to offer help to the colleague. 
While many of these experiences related to other organizational members in the workplace, some reflected emotional competence in interactions with customers:

I reflected on the issues [arising in the training intervention] with regard to my customer interaction, since that's the area where I find these skills are mostly needed, more than in the work community. For me, the focus is on patients and therefore, I've made good use of these issues in this kind of interaction. (Interview)

\section{Emotional competence embedded with workplace practices}

The third domain of emotional competence identified was embedded with workplace practices. This aspect contained reflection on the workshops, and/or the linking of emotions to various workplace routines and practices. The practices themselves could be either individual or collective; they were attached to routines such as meetings or performance appraisals, or they might be linked to physical spaces (such as coffee rooms, or the back office in company premises).

According to one of the supervisors in the company, performance appraisals were a good forum to raise discussions on emotions, and to "open people's eyes" on the importance of emotional skills, and how they concerned the entire work community:

I found [performance appraisals] were a good forum to take up the issue. To listen to everyone individually, and to try to open their eyes, especially those whose attitude was more negative, to see how this concerns the whole community at work. (Interview)

Different types of meetings typically play an important role in workplace practices, and the data show emotional competence at work to be embedded in these recurrent practices. One of the employees described how she had learnt to regulate her own work resources in meetings, by taking into account her own emotion of frustration at participating in a meeting in which her contribution was needed for just a small fraction of the time. Giving herself permission to use her time according 
to her own expert judgment was a way of regulating her emotions, and of controlling the work that was embedded in these recurrent meetings.

One participant remarked that he had noticed the benefit of using one of the new tools in meetings. This tool consisted of a framework with simple questions; these could guide the discussion onto a different level and support a new perspective on an emotional issue. His experience was that his use of the tool had improved the focus in the meetings:

[The use of the tool] really does guide, it guides the talk [in the meeting], if we are skirting around the real issues, if you can think of the right question to ask (Interview)

Another example of emotional competence at work, embedded within workplace practices, involved connections with what one could call spatial practices. This refers to the use of physical spaces in the workplace that can act as forums for various activities. For example, one respondent described how their team used one of the back offices as a place to vent anger, or other feelings that could not be expressed within customer interaction. For another member of the organization, the coffee room or the room of a close colleague acted in similar way. Reflecting on his experiences, one participant said that he had learned to notice his own emotions and those of others during coffee breaks in the coffee room. In addition to noticing such emotions, the ability to label them was considered an important skill in coping with situations.

\section{Discussion and conclusion}

The study explored emotional competence at work in the context of an emotion-focused training intervention. It identified and described individual emotional competence, emotional competence within interactions, and the emotional competence embedded within workplace practices. The present paper contributes to academic literature on emotional competence by applying a sociocultural perspective on emotion interventions, and by presenting a number of empirically grounded insights.

In promoting individual emotional competence, a major role was played by an increase in people's knowledge of emotions, greater awareness of emotions, and new skills for use in everyday 
practice. The role of knowledge as an integral element of emotional competence at work is in line with previous research by Hodzic et al. (2018), which concluded that EI training was of particular benefit to the cognitive aspect of understanding emotions. This also accords with previous literature indicating that the development of emotional skills through education can improve individuals' ability to process emotional information, and increase emotional literacy (Ashkanasy et al., 2009). Overall, it appears that increased awareness of one's own knowledge regarding emotions may have positive effects in the workplace. As suggested by Kirk et al. (2008), a belief in one's own capabilities may lead individuals to use their emotional abilities to build a collective emotional climate.

In building such a collective emotional climate, reflexivity concerning the emotions of others is important. In the present study, emotional competence was developed as organizational members learned to focus on the emotions of other persons within social situations and interactions. This supports the finding of Kemeny et al. (2012), who reported an increase in recognition of the emotions of others during an emotion-focused intervention; the researchers were of the opinion that building emotional competence in this domain may facilitate organizational lives, which are, by their very nature, collective. The present study also showed how the embedding of emotional competence within workplace practices can link increased emotional abilities to the routines and practices of the workplace. The observation that organizational members can apply emotions to workplace practice contributes to research on emotional competence, and in particular, sheds light on emotions in the organizational context - as called for by e.g. Fehr et al. (2017) and Ashkanasy et al. (2017). Overall, the findings of the study support previous studies (e.g. Huy, 2011; Kykyri \& Puutio, 2017; Manzoor et al., 2018); these have emphasized the complexity of emotions within the social processes of organizations, and the multiple interpretations that can be placed on them.

In showing how emotional competence at work can be built into the interactions and practices of organizations, the study suggests that emotion training can indeed enhance organizations in their day-to-day processes, and can support individual organizational members' transformative actions. This finding broadly supports earlier observations, that greater sensitivity towards everyday interactions within organizations may further the nurturing of awareness and empathy in organizational contexts (Rill, 2016; Senge et al., 2005). The study sheds light on the dynamics of the 
building of emotional competence in changing organizations (Huy, 1999). The findings of the study illustrate how one's awareness and knowledge of emotions can be positively enlarged by emotionfocused training interventions, giving a real stimulus to applying new-found emotional competence in real work contexts.

In methodological terms, the study emphasizes the utility of qualitative and interpretative approaches to understanding emotions in organizations. Its contribution lies in applying a qualitative approach to the study of emotion-focused interventions and emotional competence at work. It should also be noted that in contrast with most research on emotion-focused interventions - in which an individualistic approach has been followed (mostly focusing on EI) - a socio-cultural approach can adopt a broader perspective, with possibilities for capturing the organizational context as well as the individual experiences within the context. However, a number of limitations should be noted. First of all, in adopting the present socio-cultural approach, the bodily and expressive individual experience of actual feelings at work has not been addressed. In addition, in its focus on expressed emotions, the approach taken captures only the conscious aspects of emotions.

It is also obvious that, since this study was conducted in only one organization, future research could explore other organizational contexts. Furthermore, studies utilizing (for example) ethnographic strategies in a range of domains could contribute to a more comprehensive understanding of the transformations and outcomes related to emotion-driven interventions at work. It should also be noted that recent rapid technological development has resulted in new kinds of measurement technologies for real-life situations (e.g. electrodermal activity [EDA] and heart rate variability [HRV]). These seem likely to open new and exciting frontiers for emotion studies in organizational contexts (cf. Azevedo et al., 2016). In future studies, one can expect to see research frames in which both the individual/physiological and socio-cultural aspects of emotion are addressed simultaneously.

The practical implications of this study underline the pivotal importance of enhancing emotional competence in organizational change. Since emotions have such a major role in everyday practice and change within organizations (Dasborough et al., 2015; Vuori \& Virtaharju, 2012), any increase in emotional competence in the workplace is very much in the interest of managers. The study highlights the need for management to acknowledge the role of emotions in their organizations, 
and to support intra-organizational contexts that will enhance emotional competence. Indeed, one can suggest that emotion-focused interventions should be targeted at the entire personnel, in order to increase overall interactional competence among organizational members, and to embed emotional competence within general workplace practices. Resource allocation to promote collective activity, encompassing the insights gained from emotion training, would be particularly valuable when efforts are made to change routines and practices within an organization.

At the start of the paper it was proposed that a socio-cultural perspective on emotional competence at work could lead to a better understanding of emotion-focused training interventions. This indeed appears to be the case, insofar as three kinds of emotional competence were found to be manifested at work. Previous literature has noted that emotions take place on many levels in organizations, and that individual interpretations play a crucial role in organizational processes. However, the present study indicates the value of going beyond the individual level in exploring the impacts of emotion-focused interventions, with a view to capturing crucial aspects of everyday organizational practice. It can be argued that this is highly relevant for organizations and management, once one accepts the importance of emotions in the social and discursive processes of organizational meaning-making and change.

\section{References}

Ashkanasy, N.M. 2003, "Emotions in organizations: A multi-level perspective" in Multi-level issues in organizational behavior and strategy Emerald Group Publishing Limited, pp. 9-54.

Ashkanasy, N.M., Dasborough, M.T. \& Ascough, K.W. 2009, "Developing leaders: Teaching about emotional intelligence and training in emotional skills", The Sage handbook of management learning, education and development, pp. 161-183.

Ashkanasy, N.M., Humphrey, R.H. \& Huy, Q.N. 2017, "Integrating emotions and affect in theories of management", Academy of Management Review, vol. 42, no. 2, pp. 175-189.

Azevedo, R., Taub, M., Mudrick, Farnsworth, \& Martin, S. 2016, “Interdisciplinary research methods used to investigate emotions with advanced learning technologies", in Zembylas, M. and Schutz P. (Eds), Methodological Advances in Research on Emotion and Education, Dordrecht, Springer, pp. 231-243. 
Brasseur, S., Grégoire, J., Bourdu, R. \& Mikolajczak, M. 2013, "The profile of emotional competence (PEC): Development and validation of a self-reported measure that fits dimensions of emotional competence theory", Plos one, vol. 8, no. 5, pp. e62635.

Braun, V. \& Clarke, V. 2006, "Using thematic analysis in psychology", Qualitative research in psychology, vol. 3, no. 2, pp. 77-101.

Chiaburu, D.S. \& Gray, B. 2008, "Emotional incompetence or gender-based stereotyping?", The Journal of applied behavioral science, vol. 44, no. 3, pp. 293-314.

Clarke, N. 2010a, "Developing emotional intelligence abilities through team-based learning", Human Resource Development Quarterly, vol. 21, no. 2, pp. 119-138.

Clarke, N. 2010b, "The impact of a training programme designed to target the emotional intelligence abilities of project managers", International Journal of Project Management, vol. 28, no. 5, pp. 461-468.

Dasborough, M., Lamb, P. \& Suseno, Y. 2015, "Understanding emotions in higher education change management", Journal of Organizational Change Management, vol. 28, no. 4, pp. 579-590.

Eteläpelto, A., Vähäsantanen, K., Hökkä, P. \& Paloniemi, S. 2013, "What is agency? Conceptualizing professional agency at work", Educational Research Review, vol. 10, pp. 45-65.

Ekman, P. 2016, "What scientists who study emotion agree about", Perspectives on Psychological Science, vol. 11 no. 1, pp. 31-34.

Fehr, R., Fulmer, A., Awtrey, E. \& Miller, J.A. 2017, "The grateful workplace: A multilevel model of gratitude in organizations", Academy of Management Review, vol. 42, no. 2, pp. 361-381.

Hareli, S., Rafaeli, A. \& Parkinson, B. 2008, "Emotions as social entities: Interpersonal functions and effects of emotion in organizations", Research companion to emotion in organizations, pp. 349359.

Härtel, C.E., Gough, H. \& Härtel, G.F. 2006, "Service providers' use of emotional competencies and perceived workgroup emotional climate to predict customer and provider satisfaction with service encounters.", International Journal of Work Organisation and Emotion, vol. 1, no. 3, pp. $232-253$. 
Hodzic, S., Scharfen, J., Ripoll, P., Holling, H. \& Zenasni, F. 2018, "How efficient are emotional intelligence trainings: a meta-analysis", Emotion Review, vol. 10, no. 2, pp. 138-148.

Huy, Q. N. 1999, "Emotional capability, emotional intelligence, and radical change”. Academy of Management review, vol. 24, no 2, pp. 325-345.

Huy, Q. N. 2005, “An emotion-based view of strategic renewal”. Advances in strategic management, vol. 22, pp.3-37. doi.org/10.1016/S0742-3322(05)22001-6

Huy, Q.N. 2011, "How middle managers' group-focus emotions and social identities influence strategy implementation", Strategic Management Journal, vol. 32, no. 13, pp. 1387-1410.

Hökkä, P.K., Vähäsantanen, K., Paloniemi, S. \& Eteläpelto, A. 2017, "The reciprocal relationship between emotions and agency in the workplace" in Agency at Work: An agentic perspective on professional learning and development, vol. 20, Cham: Springer, pp. 161-181.

Hökkä, P., Vähäsantanen, K., Paloniemi, S., Herranen, S. \& Eteläpelto, A. 2019, "Emotions in leaders' enactment of professional agency", Journal of Workplace Learning, vol. 31, no. 2, pp. 143-165.

Kemeny, M.E., Foltz, C., Cavanagh, J.F., Cullen, M., Giese-Davis, J., Jennings, P., Rosenberg, E.L., Gillath, O., Shaver, P.R. \& Wallace, B.A. 2012, "Contemplative/emotion training reduces negative emotional behavior and promotes prosocial responses.", Emotion, vol. 12, no. 2, pp. 338.

Kim, T., Cable, D.M., Kim, S. \& Wang, J. 2009, "Emotional competence and work performance: The mediating effect of proactivity and the moderating effect of job autonomy", Journal of Organizational Behavior: The International Journal of Industrial, Occupational and Organizational Psychology and Behavior, vol. 30, no. 7, pp. 983-1000.

Kirk, B.A., Schutte, N.S. \& Hine, D.W. 2008, "Development and preliminary validation of an emotional self-efficacy scale", Personality and Individual Differences, vol. 45, no. 5, pp. $432-$ 436.

Kykyri, V. \& Puutio, R. 2018, "Conflict as it happens: Affective elements in a conflicted conversation between a consultant and clients", Journal of Organizational Change Management. Vol. aheadof-print No. ahead-of-print. https://doi-org.ezproxy.jyu.fi/10.1108/JOCM-10-2016-0222 
Livne-Tarandach, R., \& Bartunek, J. M. 2009, “A new horizon for organizational change and development scholarship: Connecting planned and emergent change". Research in organizational change and development, vol 17, no 1, pp.1-35.

Luthans, F., Avey, J.B. \& Patera, J.L. 2008, "Experimental analysis of a web-based training intervention to develop positive psychological capital", Academy of Management Learning \& Education, vol. 7, no. 2, pp. 209-221.

Ma, X., Tamir, M. \& Miyamoto, Y. 2018, "A socio-cultural instrumental approach to emotion regulation: Culture and the regulation of positive emotions." Emotion, vol. 18, no. 1, pp. 138.

Manzoor, H., Johnson, N. \& Rashid, M. U. 2018, "Emotions during executive succession in a public board", Journal of Organizational Change Management, vol. 31, no. 3, pp. 766-776.

Mayan, M.J. "Essentials of Qualitative Inquiry. 2009", Walnut Creek: Left Coast Press.

Mayer, J.D. \& Salovey, P.E. 1997, "What is emotional intelligence?" in Emotional development and emotional intelligence: Educational implications, eds. P.E. Salovey \& D.J. Sluiter, Basic Books.

Patton, M.Q. 2002, "Qualitative research and evaluation methods", $3^{\text {rd }}$ Edition. Thousand Oakes: Sage.

Pool, L.D. \& Qualter, P. 2012, "Improving emotional intelligence and emotional self-efficacy through a teaching intervention for university students", Learning and Individual Differences, vol. 22, no. 3, pp. 306-312.

Schutte, N.S., Malouff, J.M. \& Thorsteinsson, E.B. 2013, "Increasing emotional intelligence through training: Current status and future directions", International Journal of Emotional Education, vol. 5, no. 1, pp. 56.

Schutz, P. \& DeCuir, J. 2002, "Inquiry on emotions in education", Educational Psychologist, vol. 37, pp. $125-134$.

Senge, P. M. 2006, “The fifth discipline: The art and practice of the learning organization”. Broadway Business.

Senge, P. M., Scharmer, C. O., Jaworski, J., \& Flowers, B. S. 2005, "Presence: An exploration of profound change in people, organizations, and society”. Crown Business. 
Smith, R. 2017, "Three aspects of epistemological agency: The socio-personal construction of worklearning" in Agency at Work: An agentic perspective on professional learning and development, vol. 20, Cham: Springer, pp. 67-84.

Snyder, S. A., Heller, S. M., Lumian, D. S., \& McRae, K. 2013, "Regulation of positive and negative emotion: Effects of sociocultural context" Frontiers in Psychology, https://doi.org/https://doi.org/10.3389/fpsyg.2013.00259.

Sturdy, A. 2003, "Knowing the unknowable? A discussion of methodological and theoretical issues in emotion research and organizational studies", Organization, vol. 10, no. 1, pp. 81-105.

Tse, H.H.M., Troth, A.C., Ashkanasy, N.M. \& Collins, A.L. 2018, "Affect and leader-member exchange in the new millennium: A state-of-art review and guiding framework", The Leadership Quarterly, vol. 29, no. 1, pp. 135-149.

Tsoukas, H \& Chia, R. 2002, "On organizational becoming: Rethinking organizational change." Organization science, vol.13, no.5, pp. 567-582.

Turner, J. H. 2007, “Human emotions. A sociological theory”. New York: Routledge.

Voronov, M. \& Weber, K. 2016, "The heart of institutions: Emotional competence and institutional actorhood", Academy of Management Review, vol. 41, no. 3, pp. 456-478.

Vuori, T. \& Virtaharju, J. 2012, "On the role of emotional arousal in sensegiving", Journal of Organizational Change Management, vol. 25, no. 1, pp. 48-66.

Wang, N., Wilhite, S. \& Martino, D. 2016, "Understanding the relationship between school leaders' social and emotional competence and their transformational leadership: The importance of selfother agreement", Educational Management Administration \& Leadership, vol. 44, no. 3, pp. 467-490.

Zembylas, M. 2007, "Theory and methodology in researching emotions in education", International Journal of Research \& Method in Education, vol. 30, no. 1, pp. 57-72. 
Figure 1. Implementation of the project (above the time line), plus the data collected and used in this study (in grey, below the time line).

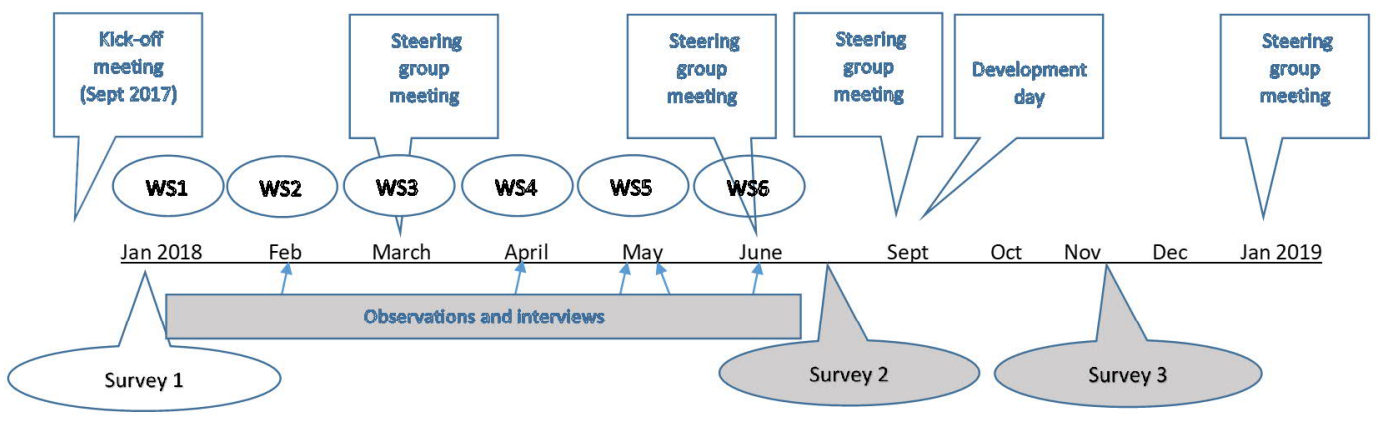

WS = workshop

Workshop contents:

WS1: Increasing emotional awareness

WS2: The forces behind emotions (psychological needs)

WS3: Awakening and strengthening positive emotions

WS4: Facing and dealing with negative emotions

WS5: Putting emotional skills into practice in everyday work

WS6: Building and leading the workplace emotional climate 
Table 1. Data and participants in the study.

\begin{tabular}{|c|c|c|c|}
\hline \multicolumn{3}{|c|}{ Data utilized in this study } & Participant description \\
\hline $\begin{array}{l}\text { Semi-structured } \\
\text { interviews ( } n=11 \text { ) }\end{array}$ & $\begin{array}{l}\text { Focusing on daily } \\
\text { work practices, and } \\
\text { experiences of the } \\
\text { emotion } \\
\text { intervention. }\end{array}$ & $\begin{array}{l}210 \text { pages of } \\
\text { transcribed } \\
\text { interview data } \\
\text { (11 hours) }\end{array}$ & $\begin{array}{l}\text { * } 5 \text { supervisors and } 6 \text { employees } \\
* 4 \text { women, } 7 \text { men } \\
\text { * Age-range: } 36-58 \text { years, mean age } 45 \text { years }\end{array}$ \\
\hline $\begin{array}{l}\text { Responses to two } \\
\text { open-ended } \\
\text { questions collected } \\
\text { in two separate } \\
\text { surveys }^{*}(n=54)\end{array}$ & $\begin{array}{l}\text { Question 1: } \\
\text { focusing on the } \\
\text { experiences of the } \\
\text { intervention. } \\
\text { Question 2: focusing } \\
\text { on the potential } \\
\text { usefulness of the } \\
\text { intervention for } \\
\text { one's current work } \\
\text { practices. }\end{array}$ & $\begin{array}{l}8 \text { pages of } \\
\text { qualitative } \\
\text { responses }\end{array}$ & $\begin{array}{l}\text { * M ost of the respondents represented employees in a non-supervisory position } \\
\text { (84\% in Survey 2; 88\% in Survey3) } \\
\text { * M ost of the respondents were women ( } 92 \% \text { in Survey 2; } 94 \% \text { in Survey 3) } \\
\text { * Age-range: } 25-63 \text { years; mean age } 42 \text { years for Survey 2; } 45 \text { years for Survey } 3\end{array}$ \\
\hline $\begin{array}{l}\text { Observation data } \\
\text { collected in two } \\
\text { separate team } \\
\text { leaders' group } \\
\text { meetings }\end{array}$ & $\begin{array}{l}\text { Focusing on the } \\
\text { experiences of the } \\
\text { intervention and } \\
\text { applying the } \\
\text { contents in work } \\
\text { practices. }\end{array}$ & $\begin{array}{l}21 \text { pages of } \\
\text { transcribed } \\
\text { meeting } \\
\text { discussions ( } 4 \\
\text { hours) } \\
6 \text { pages of field } \\
\text { notes }\end{array}$ & $\begin{array}{l}* 11 \text { supervisors } \\
* \text { M ost of the supervisors were women (81\%) }\end{array}$ \\
\hline
\end{tabular}

The survey data for the present study were collected twice: the first data collection came immediately after the intervention (Survey 2); the second, five months later (Survey 3). 